\title{
CHILDHOOD HEALTH AND DIFFERENCES IN LATE-LIFE HEALTH OUTCOMES BETWEEN ENGLAND AND THE UNITED STATES
}

\author{
James Banks \\ Zoe Oldfield \\ James P. Smith \\ Working Paper 17096 \\ http://www.nber.org/papers/w17096
NATIONAL BUREAU OF ECONOMIC RESEARCH
1050 Massachusetts Avenue
Cambridge, MA 02138

May 2011

This paper was presented at the NBER Boulders Economics of Aging Conference in May 2011. We are grateful for comments by participants at the conference and our discussant Amitabh Chandra. The research was supported by grants from the NIA. Banks and Oldfield are grateful to the Economic and Social Research Council for co-funding through the Centre for Microeconomic Analysis of Public Policy at the IFS. The views expressed herein are those of the authors and do not necessarily reflect the views of the National Bureau of Economic Research.

NBER working papers are circulated for discussion and comment purposes. They have not been peerreviewed or been subject to the review by the NBER Board of Directors that accompanies official NBER publications.

(C) 2011 by James Banks, Zoe Oldfield, and James P. Smith. All rights reserved. Short sections of text, not to exceed two paragraphs, may be quoted without explicit permission provided that full credit, including $\odot$ notice, is given to the source. 
Childhood Health and Differences in Late-Life Health Outcomes Between England and the United States

James Banks, Zoe Oldfield, and James P. Smith

NBER Working Paper No. 17096

May 2011

JEL No. I10

\begin{abstract}
In this paper we examine the link between retrospectively reported measures of childhood health and the prevalence of various major and minor diseases at older ages. Our analysis is based on comparable retrospective questionnaires placed in the Health and Retirement Study and the English Longitudinal Study of Ageing - nationally representative surveys of the age 50 plus population in America and England respectively. We show that the origins of poorer adult health among older Americans compared to the English trace right back into the childhood years - the American middle and old-age population report higher rates of specific childhood health conditions than their English counterparts. The transmission into poor health in mid life and older ages of these higher rates of childhood illnesses also appears to be higher in America compared to England. Both factors contribute to higher rates of adult illness in the United States compared to England although even in combination they do not explain the full extent of the country difference in late-life health outcomes.
\end{abstract}

James Banks

Institute for Fiscal Studies

7 Ridgemount

London, WC1 7AE U.K.

j.banks@ifs.org.uk

Zoe Oldfield

Institute for Fiscal Studies

7 Ridgemount

London, WC1 7AE U.K.

zoe_o@ifs.org.uk
James P. Smith

Labor and Pop Studies Program

The RAND Corporation

1776 Main Street

Santa Monica, CA 90406

smith@rand.org 


\section{Introduction}

International comparisons of health have risen in importance as a method of gaining insight into social and economic determinants of health status. Partly, this is due to the recent discovery and documentation of large unexplained differences in morbidity health outcomes that suggest that Americans are much sicker than their Western European counterparts (Banks, Marmot, Oldfield, and Smith, 2006; Avendano et al, 2009). In a set of recent papers, we compared disease prevalence among middle age adults 55-64 and at older ages in England and in the US (Banks Marmot, Oldfield and Smith (2006, 2009); Banks, Muriel and Smith (2010); Banks, Berkman, and Smith, 2011). Based on self-reported prevalence of seven important illnesses (diabetes, heart attack, hypertension, heart disease, cancer, diseases of the lung, and stroke), Americans were much less healthy than their English counterparts. These differences were large at all points of the SES distribution.

Biological markers of disease showed similar health disparities between Americans and the English, suggesting that these large health differences were not a result of differential reporting of illness. We also found that these health differences existed with equal force among both men and women (Banks, Marmot, Oldfield, and Smith. 2009). Since we purposely excluded minorities (African-Americans and Latinos in American and non-Whites in England), these differences were not solely due to health issues in the minority or immigrant population. Moreover, these disparities in prevalence of chronic illness were also not the consequence of differences between the two countries in conventional risk factors such as smoking, obesity, and drinking - estimates of health disparities were essentially unchanged when we controlled for different levels of these risk factors in America and in England. Models of diabetes prevalence which controlled for both BMI and waist circumference displayed much reduced country 
differences (Banks, Kumari, Smith and Zaninotto, 2011). However, the extent to which this can be interpreted as an 'explanation' of cross-country diabetes differences is somewhat limited if one views raised waist circumference for a given BMI as part of the fundamental etiology of diabetes. We still have to be able to explain why- for given levels of obesity- Americans have larger waists than the English. All in all, therefore, it remains the case that much of the USEnglish difference in later life adult health remains unexplained.

In this paper, we investigate another hypothesis to help us understand underlying reasons for the large American health disadvantage. This hypothesis is that differential prevalence and differential impacts of early life conditions, and particularly childhood health, between England and the US may have lead to differences in subsequent later-life health outcomes. Considerable evidence has emerged that variation in health outcomes at middle and older ages may be traced in part to health and other conditions during childhood (Barker, 1997, Case et al, 2002, Case et al, 2005, Currie and Stabile, 2003, Smith, 2009, Smith and Smith, 2010). In this paper, we will test whether such variation accounts for important parts of country differences in adult health.

This remainder of this paper is divided into four sections. The next section describes the data that we will use in this analysis while the section that follows compares prevalence of childhood illnesses for birth cohorts in the two countries. Section 4 summarizes the main results obtained from analytical models relating these childhood illnesses to measures of adult health. The purpose of this analysis is to assess how much of the large differences in illness at middle and older ages in America compared to England can be explained by any differences that prevailed when these people were children and adolescents. The final section of the paper highlights our main conclusions. 


\section{Childhood Health Data in the HRS and ELSA}

This research uses data from two surveys — the English Longitudinal Survey of Aging (ELSA) and the US Health and Retirement Survey (HRS). Both surveys collect longitudinal data on health, disability, economic circumstances, work, and well-being, from a representative sample of the English and American populations aged 50 and older. Both ELSA and HRS are widely viewed as strong in the measurement of socioeconomic variables (education, employment, income, wealth) and health (self-reported subjective general health status, prevalence and incidence of physical and mental disease during the post age 50 adult years (hypertension, heart disease, diabetes, stroke, chronic lung diseases, asthma, arthritis and cancer, and emotional and mental illness including depression), disability and functioning status, and several salient health behaviors (smoking, alcohol consumption, and physical activity). HRS and ELSA have both been widely used in stand alone studies as well as comparative studies of adult health.

One limitation of ELSA and HRS, along with the various other new international aging data sets, is that data collection only begins at age 50 (and even later for those cohorts who were older at the time of the initial baseline interview). Fortunately, this limitation was recognized, and many of these data sets subsequently fielded questionnaires or questionnaire modules that aimed to fill in, through retrospective recall, the more salient episodes in respondents' prebaseline life histories. Childhood events including childhood health were an important part of these life history interviews.

Both HRS and ELSA included very similar retrospectively reported childhood health histories. ELSA fielded their childhood health history between its wave 3 and wave 4 core interviews between February and August 2007. ELSA used a stand alone 'life-history' CAPI 
personal interview covering a variety of childhood circumstances and events as well as the prebaseline adult years. All ELSA respondents were eligible, and there was an eighty percent response rate $(\mathrm{N}=7,855)$. For the purposes of our analysis, the data from the life history questionnaire was combined with the data from the third wave the main interview which was fielded between June 2006 and March 2007. The HRS childhood health history was initially placed into an internet survey in 2007 for those respondents who had internet access and who agreed to be interviewed in that mode $(\mathrm{N}=3,641)$. The remainder of HRS respondents $(\mathrm{N}=12,337)$ received the same childhood health history as part of the 2008 core interview. ${ }^{1}$

In addition to a subjective question rating their childhood health before age 16 on the standard five-point scale from excellent to poor, respondents in both surveys were asked about the occurrence of a set of common childhood illnesses. If the condition did exist, they were asked the age of first onset. The list of childhood illnesses that were asked was very similar in the two surveys but not identical- some diseases were asked in one survey but not the other. ${ }^{2}$ Thus, we confine our analysis in this paper only to childhood illnesses and conditions that were asked in both surveys. Even within these set of childhood conditions, there are differences in wording or inclusion that must be taken into account. The following childhood diseases have basically the same wording in both surveys—asthma, diabetes, heart trouble, chronic ear problems, severe headaches or migraines, and epilepsy or seizures. For the common childhood infectious diseases, HRS respondents were asked about mumps, measles, and chicken pox separately while ELSA

\footnotetext{
${ }^{1}$ See Smith, 2009a for details.

${ }^{2}$ For example, the following childhood conditions and diseases were asked in ELSA but not in HRS- broken bones and fractures; appendicitis; leukemia or lymphoma; cancer or malignant tumor. The following conditions were asked in HRS but not in ELSA- difficulty seeing even with glasses or prescription lenses; a speech impairment; stomach problems; high blood pressure; a blow to the head, head injury or trauma severe enough to cause loss of consciousness or memory loss for a period of time.
} 
respondents were asked a single question about all infectious disease with the question wording mentioning these three diseases but also including polio and TB.

The biggest difference between the two surveys involves allergies and respiratory problems. In HRS, respondents were asked about respiratory disorders which included bronchitis, wheezing, hay fever, shortness of breath, and sinus infections and were separately asked about any allergic conditions. ELSA respondents were asked about allergies including hay fever and then separately about respiratory problems. Thus, hay fever shows up in a different category in the two surveys. The other difference of possible significance concerns the category of emotional and psychological problems which included two questions about depression and other emotional problems in HRS and one question about emotional, nervous, or psychiatric problems in ELSA.

In addition to any impact of these wording differences, the form in which the questions were asked also differed between the two surveys. HRS respondents were asked separate questions about each condition while ELSA respondents were shown a 'show card' which contained a list of conditions and then asked to identify any that they may have had before age 16. The show card format could lead to lower reported prevalence if respondents that had multiple conditions only identify a subset from show cards, whilst they would have answered in the affirmative to each of the questions individually had they been asked.

\section{Comparing Childhood Health in England and the USA}

Our first descriptive analysis compares prevalences of childhood conditions that are more or less comparably defined in England and the United States using these two surveys. In addition to presenting overall prevalence in the two samples, we also stratified the data by four broadly 
defined birth cohorts—-those born pre 1930, those born between 1930 and 1939, those born between 1940 and 1949, and those born in 1950 or after. Given the age selection of HRS and ELSA respondents and the fact that both samples were refreshed with younger cohorts prior to the retrospective data collection (in 2006 for ELSA and 2004 for HRS), the youngest cohort of our sample contains only those born between 1950 and 1956.

Such age stratification may reveal the nature of any secular trends in the prevalence of childhood diseases in the two countries. Given the reliance on recall for this data, however, considerable caution in interpreting any age patterns is advisable. One problem involves mortality selection if those with healthier childhoods live longer as they undoubtedly do. This is a selection effect that should become stronger at older ages.

Since these prevalence measures are based on recall, a second problem is that memory biases may be playing a role in these trends as well and these may also be stronger at older ages. It is well established that memory typically declines with time from the event (Sudman and Bradburn, 1974). Salient events may suffer less from this type of memory decay and memory of childhood happenings appear to be superior than for other times of life. Smith (2009a) shows that data from these recall histories on childhood health show similar age-cohort patterns to those collected from contemporaneous sources for example.

The third and final problem is the difficulty in separating cohort or time trends in true prevalence and incidence from improved detection or changing diagnostic thresholds. For most childhood diseases, there is very likely improved diagnosis and detection of childhood diseases over time, and for some diseases, including mental illness, there may be some effect of a lowering of the threshold for diagnosis. 
Table 1. Childhood Disease Prevalence in the HRS and ELSA (\%)

\begin{tabular}{llllllllllr}
\hline & \multicolumn{2}{c}{ Heart Disease } & \multicolumn{2}{c}{ Emotional } & \multicolumn{2}{c}{ Diabetes } & \multicolumn{2}{c}{ Epilepsy } & \multicolumn{2}{c}{ Ear } \\
& ELSA & HRS & ELSA & HRS & ELSA & HRS & ELSA & HRS & ELSA & HRS \\
\hline Pre 1930 & 0.49 & 2.06 & 1.33 & 2.63 & 0.00 & 0.11 & 0.24 & 0.34 & 5.06 & 8.56 \\
$1930-1939$ & 0.64 & 1.87 & 1.55 & 2.98 & 0.05 & 0.11 & 0.54 & 0.47 & 7.62 & 8.99 \\
$1940-1949$ & 0.93 & 2.32 & 2.38 & 3.75 & 0.00 & 0.08 & 0.59 & 0.67 & 7.28 & 9.39 \\
$1950-1956$ & 0.70 & 1.74 & 1.75 & 4.52 & 0.06 & 0.47 & 0.91 & 0.89 & 6.42 & 10.06 \\
& & & & & & & & & & \\
All & 0.73 & 2.05 & 1.85 & 3.53 & 0.02 & 0.18 & 0.59 & 0.61 & 6.80 & 9.29 \\
\hline
\end{tabular}

\begin{tabular}{llrrrrrrr}
\hline & \multicolumn{2}{c}{ Migraines } & \multicolumn{2}{c}{ Asthma } & \multicolumn{2}{c}{ Respiratory } & \multicolumn{2}{c}{ Allergies } \\
& ELSA & HRS & ELSA & HRS & ELSA & HRS & ELSA & HRS \\
\hline Pre 1930 & 2.90 & 4.47 & 2.48 & 2.33 & 7.61 & 7.12 & 3.29 & 4.50 \\
$1930-1939$ & 4.14 & 4.41 & 2.80 & 3.10 & 8.61 & 10.77 & 4.36 & 6.54 \\
$1940-1949$ & 5.64 & 5.03 & 3.38 & 4.54 & 9.65 & 12.41 & 6.19 & 9.76 \\
$1950-1956$ & 6.30 & 6.28 & 3.97 & 4.02 & 8.32 & 13.33 & 8.76 & 11.49 \\
& & & & & & & & \\
All & 4.94 & 5.04 & 3.21 & 3.69 & 8.75 & 11.27 & 5.80 & 8.42 \\
\hline
\end{tabular}

With these caveats in mind, Table 1 presents the patterns revealed in the data on the prevalence of early life health conditions in England and the United States. The first pattern of note is that across all ages in all nine childhood diseases reported prevalence is actually higher in the United States than in England. In some cases, the prevalence rates are rather close (epilepsy, migraines, and asthma), but in most cases the rates in the United States are much higher especially if we use relative risk as the metric for comparison. For example, there is a $45 \%$ higher risk of childhood allergies in the United States and a 29\% higher risk of respiratory problems in the US compared to England. Since England includes hay fever in allergies and the US in respiratory, the relative risk difference between the two countries is even higher for allergies. Similarly, even though overall prevalence is low in both countries, relative risk of childhood heart disease and diabetes is much higher in the United States. Supporting evidence for an American excess of childhood disease compared to the English comes from Martinson et al. (2011) who demonstrate using biomarker data from NHANES and the Health Survey for England that in 
more contempory times there is also an American excess of childhood disease. It is important to note that their comparisons do not rely on recall.

The second salient pattern in these data is country differences in across cohort trends. While for most childhood diseases in both countries secular trends indicate growing prevalence over time, these secular trends appear to be much sharper in the United States than in England. For example, take respiratory diseases as the first example—childhood prevalence is almost twice as high in the youngest birth cohorts compared to the oldest birth cohorts in Table 1 . The comparable figure for England is $9 \%$ higher.

We have discussed three potential difficulties in interpreting the cross-cohort trends in Table 1, namely mortality selection, imperfect recall and secular trends in diagnosis. In principal, each of these effects could also be operating differentially in England and the US, and hence affecting our cross-country comparisons as well. Of the three, the one that is most amenable to investigation is mortality selection, and particularly the concern that cohort trends in mortality selection may be rather different in the two countries.

What would be most worrying would be higher rates of mortality prior to older ages in England. This might lead one to suppose that those who had the specific childhood conditions identified in this table would be more likely to have died in England than in the US, hence leading us to measure lower prevalence in England when we interview survivors of these cohorts many years later. In previous research, we have already documented lower mortality rates in England between ages 50 and 65 (Banks, Smith and Muriel, 2010) so to further our evidence on this issue we analyzed the Human Mortality Base data ${ }^{3}$ on survival to various ages for the two countries for all cohorts born between 1934 and 1958 (data on earlier cohorts are not available for the US). The analysis (presented in Figure A1 in the Appendix) demonstrates that English

\footnotetext{
${ }^{3}$ http://www.mortality.org/
} 
cohorts were in fact more likely to survive to age 50 than their US counterparts. If childhood disease is predictive of mortality prior to age 50, we may if anything be understating the true prevalence differences between the two countries at the time these cohorts were young.

Interestingly, cohort trends in these survival probabilities are somewhat different across countries. For cohorts born from 1948 onwards the differences between countries in the likelihood of living to age 50 becomes rather more substantial than for the earlier cohorts. Once again this cohort-specific country divergence may be worrying for our analysis. But further investigation of this feature indicates that it is due to a sharp increase in the probability of living to age 1 in England after the Second World $\operatorname{War}^{4}$ for these later cohorts so that their survival rates were comparable to similar cohorts in the US whilst their predecessors had rather lower survival probabilities. When we look at cohort trends in survival to age 50 conditional on survival to age 1 , the pattern of cohort trends in the two countries is much more comparable with, in fact, an even greater advantage in favor of the English. Given that much of the diagnosis and onset of our childhood conditions will occur after age 1 it is this last evidence that we think is most relevant for our purposes here.

Turning back to the ELSA and HRS childhood data that form the core of our analysis, Table 2 compares later-life health outcomes in England and the United States, with the outcomes measured at or near to the time the retrospective data were collected (i.e. 2007 in England and 2007/8 in the US). We divide health outcomes into three groups-illnesses that we label major, those labeled minor, and those labeled 'Barker'. Major illness includes cancer, lung disease, stroke, angina, heart attack, and heart failure. Minor illness includes hypertension, diabetes, and arthritis. 'Barker' illnesses include those related to heart disease and diabetes (angina, heart

\footnotetext{
${ }^{4}$ One hypothesis is that this improvement in infant mortality in England in this period was due to better nutrition (Deaton 1976).
} 
attach, heart failure, hypertension, and diabetes)- the diseases that are at the core of the Barker hypothesis linking early life and particularly in-utero factors to later life health. For both countries, prevalence rates are stratified by age and gender in Table 2.

Table 2. Patterns of Types of Adult Illness in England and the United States

(a) Major Adult Illness

\begin{tabular}{lcccccc}
\hline & \multicolumn{2}{c}{ Male } & \multicolumn{2}{c}{ Female } & \multicolumn{2}{c}{ Total } \\
Age & ELSA & HRS & ELSA & HRS & ELSA & HRS \\
\hline $50-54$ & 0.09 & 0.18 & 0.10 & 0.20 & 0.10 & 0.19 \\
$55-59$ & 0.15 & 0.25 & 0.12 & 0.25 & 0.13 & 0.25 \\
$60-64$ & 0.25 & 0.34 & 0.24 & 0.34 & 0.25 & 0.34 \\
$65-69$ & 0.30 & 0.44 & 0.28 & 0.37 & 0.29 & 0.40 \\
$70-74$ & 0.38 & 0.55 & 0.29 & 0.42 & 0.33 & 0.48 \\
$75-79$ & 0.49 & 0.64 & 0.36 & 0.50 & 0.42 & 0.56 \\
$80-84$ & 0.48 & 0.70 & 0.37 & 0.55 & 0.42 & 0.61 \\
$85+$ & 0.45 & 0.68 & 0.43 & 0.58 & 0.43 & 0.61 \\
Total & 0.27 & 0.40 & 0.24 & 0.37 & 0.26 & 0.38 \\
\hline
\end{tabular}

(b) Minor Adult Illness

\begin{tabular}{lcccccc}
\hline & \multicolumn{2}{c}{ Male } & \multicolumn{2}{c}{ Female } & \multicolumn{2}{c}{ Total } \\
Age & ELSA & HRS & ELSA & HRS & ELSA & HRS \\
\hline $50-54$ & 0.41 & 0.53 & 0.38 & 0.60 & 0.39 & 0.56 \\
$55-59$ & 0.55 & 0.65 & 0.56 & 0.66 & 0.56 & 0.65 \\
$60-64$ & 0.63 & 0.70 & 0.64 & 0.78 & 0.63 & 0.74 \\
$65-69$ & 0.64 & 0.80 & 0.73 & 0.83 & 0.69 & 0.82 \\
$70-74$ & 0.71 & 0.82 & 0.78 & 0.86 & 0.75 & 0.84 \\
$75-79$ & 0.73 & 0.87 & 0.79 & 0.88 & 0.76 & 0.88 \\
$80-84$ & 0.74 & 0.85 & 0.85 & 0.91 & 0.81 & 0.88 \\
$85+$ & 0.74 & 0.85 & 0.82 & 0.90 & 0.79 & 0.89 \\
Total & 0.61 & 0.72 & 0.66 & 0.78 & 0.64 & 0.75 \\
\hline
\end{tabular}

(c) Barker Illness

\begin{tabular}{lcccccc}
\hline & \multicolumn{2}{c}{ Male } & \multicolumn{2}{c}{ Female } & \multicolumn{2}{c}{ Total } \\
Age & ELSA & HRS & ELSA & HRS & ELSA & HRS \\
\hline $50-54$ & 0.33 & 0.43 & 0.25 & 0.42 & 0.29 & 0.43 \\
$55-59$ & 0.45 & 0.53 & 0.38 & 0.45 & 0.42 & 0.49 \\
$60-64$ & 0.51 & 0.59 & 0.43 & 0.55 & 0.47 & 0.57 \\
$65-69$ & 0.55 & 0.70 & 0.52 & 0.64 & 0.54 & 0.67 \\
$70-74$ & 0.61 & 0.71 & 0.61 & 0.68 & 0.61 & 0.69 \\
$75-79$ & 0.69 & 0.77 & 0.66 & 0.73 & 0.67 & 0.74 \\
$80-84$ & 0.67 & 0.78 & 0.69 & 0.78 & 0.68 & 0.78 \\
$85+$ & 0.67 & 0.77 & 0.72 & 0.77 & 0.70 & 0.77 \\
Total & 0.52 & 0.62 & 0.49 & 0.59 & 0.51 & 0.60 \\
\hline
\end{tabular}


There are several salient patterns revealed in Table 2. Not surprisingly for all three disease categories, disease prevalence rises rapidly with age in both countries, with ages in the fifties and sixties witnessing the most rapid rate of increase. Most importantly, across all three categories of illness used in this Table, Americans have much higher rates of disease than the English do. This pattern of excess illness in America compared to England when defined using these aggregated disease groupings appears to be true for men and women and accords with the various findings on the more specific conditions and diseases that we have documented in our other research (Banks et al, 2006, Banks et al, 2010).

\section{Analytical Models Comparing Effects of Childhood Health on Adult Health in England and the USA}

Table 3 presents our baseline OLS models that attempt to isolate the salient country level differences in adult disease prevalence. These models contain only a quadratic in age (normalized so that age 50 is zero and defined for expositional convenience as (age-50)/10)), a gender dummy (male =1), a country dummy (US =1) and interactions of the US indicator variable with the age quadratic and gender. Not surprisingly given the patterns revealed in Table 2 , we find that all three disease groups increase with age at a decreasing rate ${ }^{5}$, there is a small but statistically significant male disease excess for major and Barker disease categories and a small (but again statistically significant) female excess for minor diseases in England. In terms of our main interest in country differences, we find a statistically significant common excess of disease in the United States. On average, and for the base case individuals (50 year old females), disease excess in the US over England is 7.2 percentage points, for major diseases, 14.5 percentage points for minor diseases, and 11.1 percentage points for Barker diseases. There is no strong

\footnotetext{
${ }^{5}$ As always, these age patterns could partially reflect cohort effects as well.
} 
evidence that this American disease excess differs across age and gender since the US interactions with these variables are not generally statistically significant.

Table 3. Modeling Country Differences in Adult Health Outcomes-Baseline Model

\begin{tabular}{lcccc}
\hline & (major) & (minor) & (major or minor) & (Barker) \\
\hline age & $0.177^{* *}$ & $0.259^{* *}$ & $0.274^{* *}$ & $0.224^{* *}$ \\
age2 & $-0.018^{* *}$ & $-0.039^{* *}$ & $-0.042^{* *}$ & $-0.028^{* *}$ \\
male & $0.037^{* *}$ & $-0.044^{* *}$ & $-0.032^{* *}$ & $0.042^{* *}$ \\
US & $0.072^{* *}$ & $0.145^{* *}$ & $0.159^{* *}$ & $0.111^{* *}$ \\
Age*US & 0.030 & -0.023 & $-0.045^{*}$ & 0.001 \\
Age2*US & -0.002 & 0.001 & 0.005 & -0.003 \\
Male*US & 0.025 & 0.002 & 0.011 & -0.001 \\
constant & 0.027 & $0.390^{* *}$ & $0.423^{* *}$ & $0.233^{* *}$ \\
& & & & \\
$N$ & 19,583 & 19,583 & 19,583 & 19,583 \\
\hline Note to table: * indicates $\mathrm{p}<0.05 ; * *$ indicates $\mathrm{p}<0.01$ & &
\end{tabular}

In the Tables that follow, we expand the models in Table 3 with additional groups of covariates with an eye toward examining the marginal impact of these additions on the country level main effect differences in adult health status. The added covariates in Table 4 include our few available common measures of childhood circumstances, parental background and SES. These measures are (a) whether the mother or father of the respondent was dead at the time of the collection of the retrospective data, and if so their age of death which could be seen as measures of shared familial environment during the childhood years and/or genetic factors; (b) whether your SES was low during the childhood years based on fathers occupation when you were sixteen years old ; (c) adult height measured in centimeters (normalized to mean height 65 inches), an often used summary statistic to capture elements of the Barker hypothesis related to childhood nutrition. Once again, all variables in these models are interacted with a country dummy (US=1). These new variables in (a) and (c) could equally well be thought of as alternative indicators of childhood health. Parents and children shared genes forever and 
environment for at least decades so that parental deaths and/or date of death may pick up elements of health transmitted from parents to their children. Even more so, adult height is often used as a summary statistic for childhood health, or at least the nutritional components of childhood health and as a marker for Barker related diseases.

Table 4. Modeling Country Differences in Adult Health Outcomes-Adding Childhood SES Controls

\begin{tabular}{|c|c|c|c|c|}
\hline & (major) & (minor) & (major or minor) & (Barker) \\
\hline$\overline{\text { age }}$ & $0.178 * *$ & $0.245 * *$ & $0.259 * *$ & $0.200 * *$ \\
\hline age & $-0.019 * *$ & $-0.038 * *$ & $-0.040 * *$ & $-0.026 * *$ \\
\hline male & $0.047 * *$ & -0.022 & -0.021 & $0.090 * *$ \\
\hline mother died & $0.120 * *$ & $0.118 * *$ & $0.107 * *$ & $0.156 * *$ \\
\hline mother age died & $-0.001 * *$ & $-0.001 * *$ & $-0.001 *$ & $-0.001 * *$ \\
\hline father died & $0.078 *$ & $0.101 * *$ & $0.123 * *$ & $0.183 * *$ \\
\hline father age died & -0.001 & $-0.001 * *$ & $-0.002 * *$ & $-0.002 * *$ \\
\hline ses_low & 0.014 & $0.040 * *$ & $0.038 * *$ & $0.037 * *$ \\
\hline height & -0.002 & $-0.004 *$ & -0.002 & $-0.009 * *$ \\
\hline US & $0.069 *$ & $0.120 * *$ & $0.150 * *$ & $0.098 * *$ \\
\hline Age*US & -0.002 & -0.042 & $-0.074 * *$ & -0.011 \\
\hline age $2 * U S$ & 0.004 & 0.005 & $0.010^{*}$ & 0.001 \\
\hline male*US & 0.024 & -0.004 & 0.013 & -0.023 \\
\hline mom died*US & 0.021 & -0.045 & -0.017 & -0.007 \\
\hline mom age died* US & 0.000 & 0.001 & 0.000 & 0.000 \\
\hline dad died*US & 0.077 & 0.012 & -0.012 & 0.018 \\
\hline dad age died*US & -0.001 & 0.001 & $0.001 *$ & 0.000 \\
\hline ses low*US & 0.013 & -0.020 & -0.017 & -0.004 \\
\hline height*US & 0.001 & 0.002 & 0.000 & 0.005 \\
\hline constant & -0.019 & $0.359 * *$ & $0.380 * *$ & $0.166 * *$ \\
\hline$N$ & 19,583 & 19,583 & 19,583 & 19,583 \\
\hline
\end{tabular}

Note to table: * indicates $\mathrm{p}<0.05$; ** indicates $\mathrm{p}<0.01$; Base group is a 50 -year old female with mother and father alive, average height and high childhood SES.

Examining the effects of new variables included in these models, all forms of adult disease are higher if either the mother or father of the respondent was dead at the time of the HRS or ELSA survey interview—an effect that is larger the younger the age at which parent died. The effect of these variables is not generally statistically significantly different in the two 
countries though. Through either shared family environment or genetics, having a parent die at a younger age may indicate greater shared familial proneness to illness. Particularly for minor and Barker diseases, adult levels of disease are higher among those who were a member of a low SES family during their childhood years. Finally, consistent with Barker's hypothesis, taller adults are also healthier adults. This association is especially strong for the Barker category of disease.

Once again and somewhat remarkably, very few of the interactions of variables with the US country indicator are statistically significant with the exception of the US main effect which still signals statistically significantly higher levels of disease in America compared to England on average. This US level effect is only slightly smaller in Table 4 compared to that obtained in the baseline models in Table 3 indicating that this set of childhood SES/parental health measures do not contribute very much to 'explaining' the country difference in adult health.

Our first attempt to evaluate the contributory role of childhood health towards country level adult disease differences is contained in Table 5 which adds to the set of variables in models in Table 4 the summary childhood measure of subjective health status, i.e. whether the respondents reports that they had excellent or very good health as a child. The other covariates are not appreciably altered by this addition of childhood subjective health so we will confine our discussion to the subjective childhood health measures. The estimated effect of being in excellent or very good health during one's childhood years is to lower the probability of all forms of adult disease. This association also appears to be statistically significantly larger in the United States compared to England, but only for the major disease category.

However, the estimated overall average adult health differences between America and England in Table 5 has remained essentially unchanged compared to those in Table 4 and in the 
case of major illnesses has actually increased from 0.069 to 0.102 . If childhood health problems raise the probability of adult health problems and if, as the data in Table 1 indicate, there are more such problems in America than in England, how is it possible that these problems fail to explain the between country health difference or even more perversely make them even larger?

Table 5. Modeling Country Differences in Adult Health Outcomes-Adding Childhood Subjective Health

\begin{tabular}{|c|c|c|c|c|}
\hline & $\begin{array}{c}\text { (major) } \\
\text { b }\end{array}$ & $\begin{array}{c}\text { (minor) } \\
\mathrm{b}\end{array}$ & $\begin{array}{c}\text { (major or minor) } \\
\mathrm{b}\end{array}$ & $\begin{array}{c}\text { (Barker) } \\
\mathrm{b}\end{array}$ \\
\hline age & $0.174 * *$ & $0.241 * *$ & $0.255^{* *}$ & $0.199 * *$ \\
\hline age2 & $-0.018 * *$ & $-0.037 * *$ & $-0.039 * *$ & $-0.026 * *$ \\
\hline male & $0.047 * *$ & -0.023 & -0.021 & $0.090 * *$ \\
\hline mother died & $0.117 * *$ & $0.115 * *$ & $0.103 * *$ & $0.154 * *$ \\
\hline mother age died & $-0.001 * *$ & $-0.001 *$ & $-0.001 *$ & $-0.001 * *$ \\
\hline father died & $0.075^{*}$ & $0.097 * *$ & $0.119 * *$ & $0.181 * *$ \\
\hline father age died & -0.001 & $-0.001 * *$ & $-0.002 * *$ & $-0.002 * *$ \\
\hline ses_low & 0.013 & $0.039 * *$ & $0.037 * *$ & $0.036 * *$ \\
\hline height & -0.002 & -0.004 & -0.002 & $-0.009 * *$ \\
\hline exc health as child & $-0.047 * *$ & $-0.053 * *$ & $-0.057 * *$ & $-0.024 *$ \\
\hline US & $0.102 * *$ & $0.121 * *$ & $0.145^{* *}$ & $0.117 * *$ \\
\hline Age*US & 0.001 & -0.040 & $-0.072 * *$ & -0.010 \\
\hline age $2 * U S$ & 0.004 & 0.005 & $0.010^{*}$ & 0.000 \\
\hline male*US & 0.023 & -0.005 & 0.012 & -0.024 \\
\hline mother died*US & 0.018 & -0.044 & -0.016 & -0.008 \\
\hline mother age died*US & 0.000 & 0.001 & 0.000 & 0.000 \\
\hline father died*US & 0.074 & 0.013 & -0.011 & 0.017 \\
\hline father age died*US & -0.001 & 0.001 & $0.001 *$ & 0.000 \\
\hline ses_low*US & 0.013 & -0.019 & -0.016 & -0.004 \\
\hline height*US & 0.001 & 0.002 & 0.000 & 0.005 \\
\hline ex health as child*US & $-0.031 *$ & 0.006 & 0.014 & -0.019 \\
\hline constant & 0.018 & $0.401 * *$ & $0.426 * *$ & $0.185^{* *}$ \\
\hline$N$ & 19,583 & 19,583 & 19,583 & 19,583 \\
\hline
\end{tabular}

Note to table: * indicates $\mathrm{p}<0.05$; ** indicates $\mathrm{p}<0.01$. Base group is a 50 -year old female with mother and father alive, average height, high childhood SES and good/fair/poor self-reported childhood health.

Table 6 provides the answer by displaying country differences in excellent or very good subjective childhood health as a child by birth cohort in both England and the USA. In spite of the fact that the data in Table 1 show that in almost all childhood diseases for all birth cohorts 
that Americans were sicker as children than their English counterparts, Table 6 indicates that when asked to evaluate their childhood health on a subjective scale that Americans respond that their childhoods were healthier than the responses of the English would indicate about their own English childhood. The problem with using the childhood subjective health scale is actually the same as the problem with using the adult variant of these scales- given the same objective level of health on subjective scales Americans will report themselves as healthier than the English (Banks et al, 2009; Kapteyn, Smith, and van Soest, 2007). For example the fraction of ELSA respondents who report in excellent or very good childhood health is 0.68 while in HRS it is 0.78- a ten point differential in favor of the Americans. Because of this, and since being in excellent of very good child as a child is associated with better adult health in both countries, this will make the unexplained country adult health difference even larger.

Table 6. Fraction in Excellent of Very Good Health during Childhood in the HRS and ELSA

\begin{tabular}{lcccccc}
\hline & \multicolumn{2}{c}{ Male } & \multicolumn{2}{c}{ Female } & \multicolumn{2}{c}{ Total } \\
& ELSA & HRS & ELSA & HRS & ELSA & HRS \\
\hline Pre 1930 & 0.62 & 0.70 & 0.64 & 0.70 & 0.63 & 0.70 \\
$1930-1939$ & 0.68 & 0.76 & 0.61 & 0.78 & 0.64 & 0.77 \\
$1940-1949$ & 0.68 & 0.79 & 0.68 & 0.82 & 0.68 & 0.88 \\
$1950-1956$ & 0.77 & 0.81 & 0.71 & 0.79 & 0.74 & 0.80 \\
& & & & & & \\
All & 0.69 & 0.77 & 0.66 & 0.78 & 0.68 & 0.78 \\
\hline
\end{tabular}

Putting aside for a moment this problem of country differences in subjective scales, the within country patterns revealed in Table 6 are also of interest. The within country gender differences in subjective childhood health is not large. However, there is a clear and very pronounced trend across cohort in both countries where subjective childhood health is reported to be better among the more recent cohorts. If we compare most recent cohorts in Table 6 to the 
oldest cohorts, the increase in the fraction in excellent or very good health as a child is about ten percentage points in both England and America. Whilst it is possible that childhood health improved across these cohorts (contrary to the evidence on chronic diseases presented in Table 1 above, and subject to the various caveats and especially to the role of improved diagnosis we identified in the discussion of that table) the magnitude of this increase seems rather implausible, particularly in the presence of health survivor effects which would tend to work across cohorts in the opposite direction. This points to another major puzzle in the reconciliation of secular trends in subjective and objective childhood health measures.

Table 7 extends our modeling of adult health in Table 6 by adding the set of childhood disease indicators to the model as well as interactions of this set of childhood diseases with the US country indicator variable. Since the prevalence rates of some of these childhood diseases are low, we aggregated them into six groups. The six groups are ear problems, respiratory, allergies, asthma, rare diseases (childhood diabetes, epilepsy, emotional), and all others. Main effects and interactions with the US country indicator are included in the model. Because of the across country scale comparability issue mentioned above, the model estimated in Table 7 does not include the subjective childhood health variable.

Once again, coefficients of other variables in the model are not significantly affected by adding childhood disease indicators. The diseases that appear to have most consistently statistically significant main effects are ear problems, respiratory diseases, and rare diseases. Especially for major illness, transmission into poorer adult health appears to be stronger in the US for rare diseases and for asthma. 
Table 7. Modeling Country Differences in Adult Health Outcomes-Adding Childhood Disease Indicators

\begin{tabular}{|c|c|c|c|c|}
\hline & (major) & (minor) & (major or minor) & (Barker) \\
\hline age & $0.175 * *$ & $0.244 * *$ & $0.258 * *$ & $0.201 * *$ \\
\hline age2 & $-0.018 * *$ & $-0.037 * *$ & $-0.039 * *$ & $-0.026 * *$ \\
\hline male & $0.052 * *$ & -0.019 & -0.016 & $0.090 * *$ \\
\hline mother died & $0.120 * *$ & $0.115 * *$ & $0.104 * *$ & $0.153 * *$ \\
\hline mother age died & $-0.001 * *$ & $-0.001 *$ & $-0.001 *$ & $-0.001 * *$ \\
\hline father died & $0.080 *$ & $0.101 * *$ & $0.123 * *$ & $0.182 * *$ \\
\hline father age died & -0.001 & $-0.002 * *$ & $-0.002 * *$ & $-0.002 * *$ \\
\hline ses_low & 0.016 & $0.040 * *$ & $0.039 * *$ & $0.036 * *$ \\
\hline height & -0.002 & $-0.004 *$ & -0.002 & $-0.009 * *$ \\
\hline ear problems & $0.045 *$ & 0.011 & 0.017 & -0.014 \\
\hline respiratory & $0.092 * *$ & $0.044 *$ & $0.073 * *$ & 0.017 \\
\hline allergies & -0.022 & -0.036 & -0.036 & -0.027 \\
\hline asthma & 0.039 & 0.006 & 0.003 & 0.015 \\
\hline rare & 0.027 & $0.058 * *$ & $0.063 * *$ & 0.027 \\
\hline all other & -0.004 & -0.000 & -0.009 & -0.018 \\
\hline US & 0.041 & $0.110 * *$ & $0.142 * *$ & $0.080^{*}$ \\
\hline age*US & 0.005 & -0.041 & $-0.072 * *$ & -0.010 \\
\hline age $2 * U S$ & 0.004 & 0.005 & $0.011 *$ & 0.001 \\
\hline male*_US & 0.027 & -0.004 & $0.011 *$ & -0.020 \\
\hline mother died*US & 0.019 & -0.041 & -0.013 & -0.005 \\
\hline mother age died $*$ US & 0.000 & 0.001 & 0.000 & 0.000 \\
\hline father died*US & 0.071 & 0.010 & -0.014 & 0.017 \\
\hline father age died*US & -0.001 & 0.001 & $0.001 *$ & 0.000 \\
\hline ses_low*US & 0.013 & -0.019 & -0.017 & -0.003 \\
\hline height*US & 0.001 & 0.002 & 0.001 & 0.005 \\
\hline ear problems*US & 0.002 & 0.027 & 0.015 & 0.045 \\
\hline respiratory*US & -0.030 & -0.018 & $-0.042 *$ & -0.008 \\
\hline allergies*US & 0.030 & 0.042 & 0.039 & 0.030 \\
\hline asthma*US & 0.055 & -0.005 & 0.020 & 0.015 \\
\hline rare*US & $0.101 * *$ & -0.015 & -0.022 & 0.035 \\
\hline all other*US & 0.024 & 0.021 & 0.030 & 0.023 \\
\hline constant & -0.034 & $0.350 * *$ & $0.370 * *$ & $0.167 * *$ \\
\hline$N$ & 19,583 & 19,583 & 19,583 & 19,583 \\
\hline
\end{tabular}

Note to table: * indicates $\mathrm{p}<0.05$; ** indicates $\mathrm{p}<0.01$. Base group is a 50 -year old female with mother and father alive, average height, high childhood SES, good/fair/poor self-reported childhood health and no specific childhood health conditions. 
Table 8 provides a summary of the estimated main effect American excess of disease from our models in Tables 3 to 7 . If we compare the estimates from Table 7 with the age adjusted 'raw' country differences from Table 3, the combination of SES/parental health transmission variables and the childhood diseases does 'explain' a significant part of the country differences. For example for major diseases, the raw difference in Table 3 was 7.2 percentage points of excess disease in America. The adjusted difference in Table 4 is 4.1 percentage points (and not statistically significant) so that using this metric $43 \%$ of the American excess major disease is explained compared to the base case model

Table 8 Summary Table of Estimated US excess adult illness

\begin{tabular}{|c|c|c|c|}
\hline Model & Major & Minor & Barker \\
\hline Baseline (Table 3) & $0.072 * *$ & $0.145 * *$ & $0.111 * *$ \\
\hline + childhood SES (Table 4) & $0.069^{*}$ & $0.120 * *$ & $0.098 * *$ \\
\hline + Childhood subjective health (Table 5) & $0.102 * *$ & $0.121 * *$ & $0.117 * *$ \\
\hline + Childhood diseases (Table 7) & 0.041 & $0.110 * *$ & $0.080^{*}$ \\
\hline $\begin{array}{l}\text { + Childhood diseases but without US } \\
\text { interaction with disease (Table A.1) }\end{array}$ & $0.082 *$ & $0.113^{*}$ & $0.113 * *$ \\
\hline
\end{tabular}

The comparable numbers for minor diseases is a 14.5 percentage point 'raw' disease excess in America and an 11.1 percentage point adjusted excess so that $23 \%$ of the excess is explained. Finally, for the Barker diseases, the comparable numbers are 11.1 'raw' and 8.0 'adjusted' so that $28 \%$ of the American excess is explained.

As a final note, it is instructive to consider the degree to which this 'explanation' of the excess disease in the US arises from the inclusion in the model of the indicators of prevalence of the specific childhood illnesses themselves as opposed to the interactions of these prevalence 
indicators with the US country dummy. To investigate this we ran a similar model to that presented in Table 7 but with the childhood health country interaction terms excluded (full estimates presented in Table A1 in the Appendix and estimates of the US intercept term presented in the final row of Table 8). On comparison of these results with those discussed above, it is apparent that the main contribution to the reduction in both the size and statistical significance of the US country effect arises from the inclusion of the interaction terms - whilst there is some role for the greater prevalence of childhood conditions in the US, it is the differential impacts of these childhood conditions on later-life health outcomes in the US that has the main effect on changing the coefficient on the US dummy variable. Whilst these interaction terms are, of course, just another form of 'country effect', this does suggest that investigation of the mechanisms by which early-life health is transmitted to late-life disease outcomes in the two countries would be a promising avenue for future research.

\section{Conclusions}

Differences in prevalence of childhood diseases between England and the United States and a higher rate of transmission into poorer adult health in the United States do appear to contribute to higher rates of adult illness in the United States compared to England. Our results in this paper show that, based on comparable retrospective questionnaires placed in HRS and ELSA- nationally representative surveys of the age 50 plus population in America and England respectively, the origins of poorer adult health among older Americans compared to the English traces back right into the childhood years. The transmission rates of these higher rates of childhood illnesses into poor health in mid life and older ages also appears to be higher in America compared to England. 
Of course, every partial answer raises yet another question. In this case, conditions in America appear to make people of all ages sicker than the English. This conclusion highlights a caution that age specific answers to the question of why Americans are sicker may not serve as a useful guide to uncovering the more fundamental causes of this important question. Our research shows that the primary sources of the American excess in disease are not unique to mid adulthood or old age but are more common throughout the age distribution of the two populations. Finally, it is worth noting that we are dealing in this research with the onset of disease rather than the treatment of disease so that the medical system and availability of health insurance are not likely to be the primary actors in this puzzle. This is particularly true given our use of a non-Hispanic white sample so $95 \%$ of our American sample have access to health insurance. 


\section{References}

Avendano, M., M. Glymour, J. Banks, and J.Mackenbach. (2009). Health disadvantage in US adults Aged 50-74: Are poor Europeans healthier than Americans? American Journal of Public Health 99:540-48.

Banks J., M. Marmot, Z. Oldfield, and J.P. Smith. (2006). Disease and disadvantage in the United States and in England. JAMA 295(17):2037-45.

Banks, J., M. Marmot, Z. Oldfield, and J.P. Smith. (2009). SES and health on both sides of the Atlantic. Pp. 359-406 in Developments in the Economics of Aging, edited by D. Wise. Chicago, IL: University of Chicago.

Banks, J., A. Muriel, and J.P. Smith. (2010). Disease prevalence, disease incidence, and mortality in the United States and in England. Demography 47 (Supplement):S211-31.

Banks, J., M. Kurmari, J.P. Smith, and P. Zaninotto. (2011). What explains the American disadvantage in health compared to the English? The case of Diabetes. Forthcoming in Journal of Epidemiology and Community Health.

Banks, J., L. Berkman, and J.P. Smith (2011). Do cross country variations in social integration and social interactions explain differences in life expectancy in industrialized countries? In E. Crimmins, S. Preston, and B. Cohen (eds.), International Differences in Mortality in Older Ages: Dimensions and Sources. Washington DC: National Academy Press, pp. 210-267.

Barker, D.J.P. (1997). Maternal nutrition, fetal nutrition and diseases in Later Life. Nutrition 13(9):80713.

Case, A., D. Lubotsky, and C. Paxson. (2002). Economic status and health in childhood: The origins of the gradient. American Economic Review 92(5):1308-34.

Case, A., A. Fertig, and C. Paxson. (2005). The lasting impact of childhood health and circumstance. Journal of Health Economics 24(2):365-89.

Currie, J., and M. Stabile. (2003). Socioeconomic status and child health—Why is the relationship stronger for older xhildren? American Economic Review 93(5):1813-23.

Deaton, Angus S. (1976). The structure of demand in Europe 1920-1970. in Carlo M Cippola, The Fontana Economic History of Europe, Vol 5

Human Mortality Database. University of California, Berkeley (USA), and Max Planck Institute for Demographic Research (Germany). Available at www.mortality.org

Kapteyn, A., van Soest, A. and Smith, JP "Vignettes and Self-Reported Work Disability in the US and the Netherlands," American Economic Review 97(1):461-473, March 2007. 
Martinson, M. L., Teitler, J.L, and Reichman, N.E. Health Across the Life Span in the United States and England. American Journal of Epidemiology Advance Access published March 9, 2011

Smith, J.P., and G. Smith (2010). Long-term economic costs of psychological problems during childhood. Social Science and Medicine 71(1):110-15.

Smith, J.P. (2009a). Reconstructing childhood health histories. Demography, 46(2), 387-403.

Smith, J.P. (2009b). The impact of childhood health on adult labor market outcomes. The Review of Economics and Statistics 91(3):478-89. 


\section{APPENDIX}

Table A.1 Modeling Country Differences in Adult Health Outcomes-Adding Childhood Disease Indicators without Interaction Terms

\begin{tabular}{|c|c|c|c|c|}
\hline & $\begin{array}{c}\text { (major) } \\
\mathrm{b}\end{array}$ & $\begin{array}{c}\text { (minor) } \\
\mathrm{b}\end{array}$ & $\begin{array}{c}\text { (major or minor) } \\
\mathrm{b}\end{array}$ & $\begin{array}{c}\text { (Barker) } \\
\mathrm{b}\end{array}$ \\
\hline$\overline{\text { age }}$ & $0.175 * *$ & $0.240 * *$ & $0.255^{* *}$ & $0.199 * *$ \\
\hline age2 & $-0.018 * *$ & $-0.036 * *$ & $-0.039 * *$ & $-0.026 * *$ \\
\hline male & $0.055 * *$ & -0.019 & -0.017 & $0.093 * *$ \\
\hline mother died & $0.117 * *$ & $0.114 * *$ & $0.103 * *$ & $0.153 * *$ \\
\hline mother age died & $-0.001 * *$ & $-0.001 *$ & $-0.001 *$ & $-0.001 * *$ \\
\hline father died & $0.077 *$ & $0.099 * *$ & $0.121 * *$ & $0.182 * *$ \\
\hline father age died & -0.001 & $-0.001 * *$ & $-0.002 * *$ & $-0.002 * *$ \\
\hline ses_low & 0.016 & $0.040 * *$ & $0.038 * *$ & $0.037 * *$ \\
\hline height & -0.002 & $-0.004 *$ & -0.002 & $-0.009 * *$ \\
\hline exc health as child & $-0.023 *$ & $-0.045 * *$ & $-0.047 * *$ & -0.018 \\
\hline ear problems & $0.044 *$ & $0.025^{*}$ & $0.023 *$ & 0.015 \\
\hline respiratory & $0.069 * *$ & $0.026^{*}$ & $0.040 * *$ & 0.009 \\
\hline allergies & -0.003 & -0.009 & -0.012 & -0.007 \\
\hline asthma & $0.064 * *$ & -0.008 & 0.005 & 0.018 \\
\hline rare & $0.090 * *$ & $0.042 * *$ & $0.042 * *$ & $0.047 * *$ \\
\hline all other & 0.007 & 0.007 & 0.005 & -0.006 \\
\hline US & $0.082 *$ & $0.113 *$ & $0.136 * *$ & $0.113 * *$ \\
\hline Age*US & 0.003 & -0.039 & $-0.070 * *$ & -0.010 \\
\hline age $2 * U S$ & 0.004 & 0.005 & $0.010 *$ & 0.000 \\
\hline male*US & 0.023 & -0.005 & 0.013 & -0.024 \\
\hline mother died*US & 0.019 & -0.044 & -0.015 & -0.007 \\
\hline mother age died*US & 0.000 & 0.001 & 0.000 & 0.000 \\
\hline father died*US & 0.071 & 0.010 & -0.011 & 0.017 \\
\hline father age died*US & -0.001 & 0.001 & $0.001 *$ & 0.000 \\
\hline ses_low*US & 0.012 & -0.019 & -0.016 & -0.004 \\
\hline height*US & 0.001 & 0.002 & 0.000 & $0.005^{*}$ \\
\hline ex health as child*US & -0.020 & 0.011 & 0.019 & -0.015 \\
\hline constant & -0.027 & $0.385 * *$ & $0.407 * *$ & $0.173 * *$ \\
\hline$N$ & 19,583 & 19,583 & 19,583 & 19,583 \\
\hline
\end{tabular}


Figure A1: Survival probabilities in England and Wales compared to the United States by date of birth cohort

Figure 1(a)

Probability of surviving to age 50

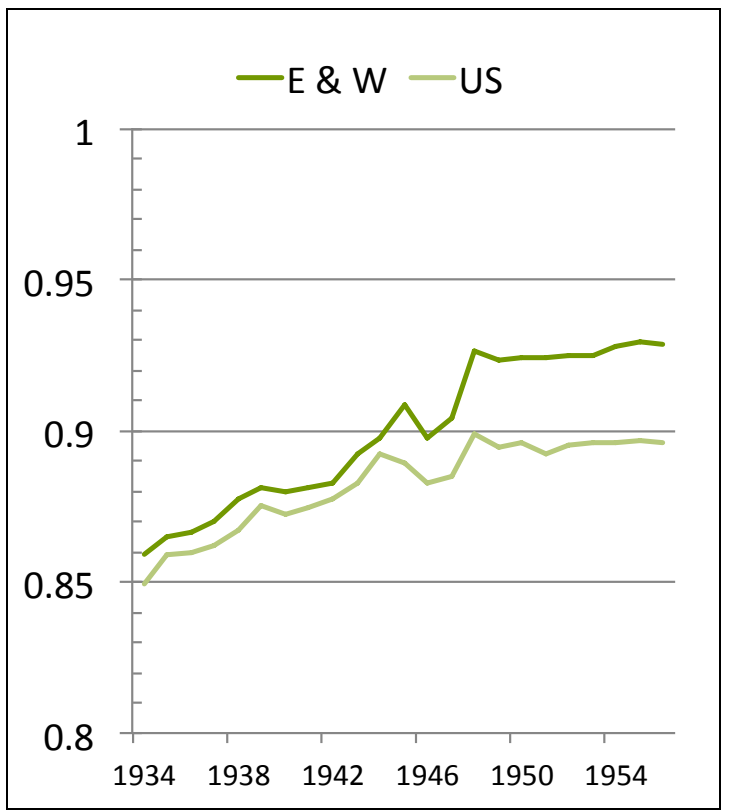

Figure 1(b)

Probability of surviving to age 1

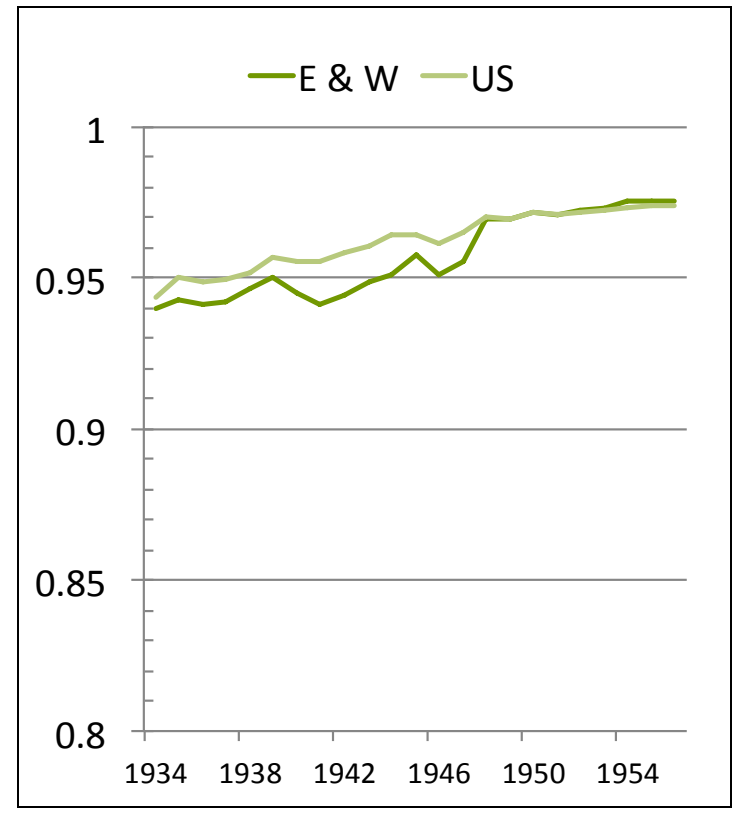

Figure 1(c)

Probability of surviving to age 50, conditional on surviving to age 1

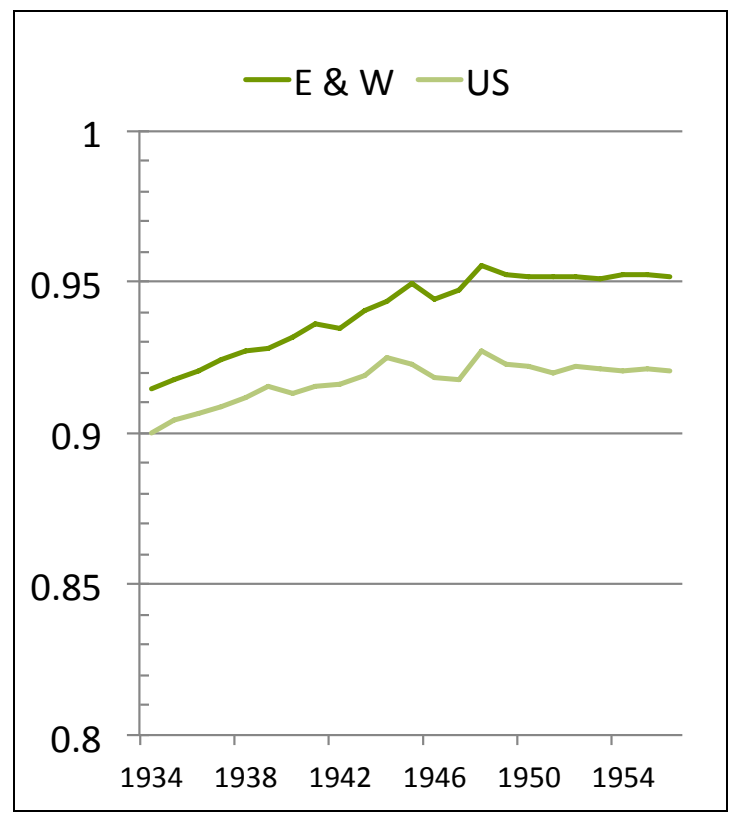

Source: Authors' calculations from Human Mortality Database 